\title{
安定化気泡関数有限要素法を用いた 非圧縮粘性流れにおける形状同定解析
}

\author{
IDENTIFICATION ANALYSIS FOR INCOMPRESSIBLE VISCOUS FLOW \\ USING STABILIZED BUBBLE FUNCTION FINITE ELEMENT METHOD
}

\author{
松本純一* \\ Junichi MATSUMOTO \\ $*$ 正会員 工博 産業技術総合研究所 計算科学研究部門, PRESTO, JST（３05-8568 つくば市梅園 1-1-1 中央第二）
}

\begin{abstract}
Numerical solutions for shape identification of flow past a circular cylinder are treated in this paper. The Sakawa-Shindo method is employed as a minimization algorithm. Thus, unified computational approach to the simulation of flow and the shape identification is presented. As a numerical approach to spatial discretization, mixed interpolations by the stabilized bubble function and linear elements are applied for velocity and pressure.
\end{abstract}

Key Words : Identification Analysis, Incompressible Viscous Flow, Stabilized Bubble Function Finite Element Method

\section{1. 緒言}

近年, コンピュータの急速な発達および並列計算の普 及により，非圧縮 Navier-Stokes 方程式を用いた大規模 な 3 次元計算が行われている. また, 数值解析の応用問 題として流体問題の計算において逆解析理論を用いた 定常 Stokes 方程式の形状最適化問題の解析1)2)3)4)5)6), 低レイノルズ数における定常 Navier-Stokes 方程式の形 状最適化問題の解析7)8)方行われている. 本研究では, その応用問題として, 非圧縮 Navier-Stokes 方程式に おける形状同定解析を行うものである. 制御・同定な どの逆問題を扱う場合には，その制御・同定量を求め るために，対象としている流れ場の状態方程式に対す る随伴方程式を導き, 状態方程式, 随伴方程式をそれ ぞれ解いていかなければならない。さらに，これらの 未知量をもとに最小化手法を適用して制御・同定量を 反復計算により求めなければならない. 以上の計算は, 通常の計算（順解析）に比べて非常に定式化が複雑に なる9)。このことから, 状態方程式, 随伴方程式の定 式化として，できるだけ簡便な安定化手法をともなう 離散化が有効となる．本研究では，これらの問題に対 して従来提案されている解析手法に比べ計算を安定に かつ高精度に行い, 極めて簡便に安定化手法の定式化 を行うことのできる安定化気泡関数有限要素法9)10)11) を適用し，非圧縮 Navier-Stokes 方程式における評価 関数に流体力を用いた形状同定解析を行うものである.
検証の問題として, 円柱周りの計算を取り上げ, レイ ノルズ数 0.1(Stokes 流れとなる領域), 20 (カルマン渦 の発生しない領域）, 250（カルマン渦が発生する領域） の 3 ケースの抗力の同定形状解析を行っている.

\section{2. 基礎方程式}

非圧縮粘性流れにおける基礎方程式は以下の運動方 程式と連続式によって表される.

$$
\begin{gathered}
\dot{u}_{i}+u_{j} u_{i, j}+p_{, i}-\nu\left(u_{i, j}+u_{j, i}\right)_{, j}=0 \quad \text { in } \quad \Omega(1) \\
u_{i, i}=0 \quad \text { in } \quad \Omega
\end{gathered}
$$

ここで, $u_{i}, p$ は流速, 圧力, また $\nu=1 / R e$ であり, Re はレイノルズ数である. 境界 $\Gamma$ は $\Gamma_{1}$ と $\Gamma_{2}$ に分け られ，以下の境界条件が規定される。

$$
\begin{gathered}
u_{i}=\hat{u}_{i} \quad \text { on } \Gamma_{1} \\
\left\{-p \delta_{i j}+\nu\left(u_{i, j}+u_{j, i}\right)\right\} \cdot n_{j}=t_{i} \text { on } \Gamma_{2}
\end{gathered}
$$

ここで, $\delta_{i j}$ はクロネッカーのデル夕関数, $n_{j}$ は境界 $\Gamma_{2}$ の外向き法線ベクトルである.

\section{3. 安定化気泡関数要素を用いた定式化}

\subsection{MINI 要素}

本研究では, 流体の基礎方程式における空間方向の 定式化として, 混合補間を用いる。ここで, 混合補間 
の組み合わせとして MINI 要素10) は混合補間を用いた 手法の中で最も自由度が少なく, かつ定式化が極めて 容易に行える要素である. また, 計算を安定にかつ高 精度に行うための安定化項の考慮がSUPG/PSPG 法 12), BTD 法 ${ }^{13)}$ などの安定化手法に比べて非常に簡単 に行える. さらに, 混合補間の要素の選択として, 流 速に高次の要素を用いる場合には, 質量行列を集中化 することは不可能であるが, MINI 要素は質量行列の 集中化が可能である. したがって, 流速に高次要素を 用いる他の混合補間に比べて, 極めて計算効率がよい 手法であると考えられる，上記理由により，混合補間 の組み合わせとして, MINI 要素を用いるものとする. すなわち, 要素の選択として, 流速に関しては気泡関 数要素を圧力に関しては 1 次要素を補間関数に用いる (図-1参照).

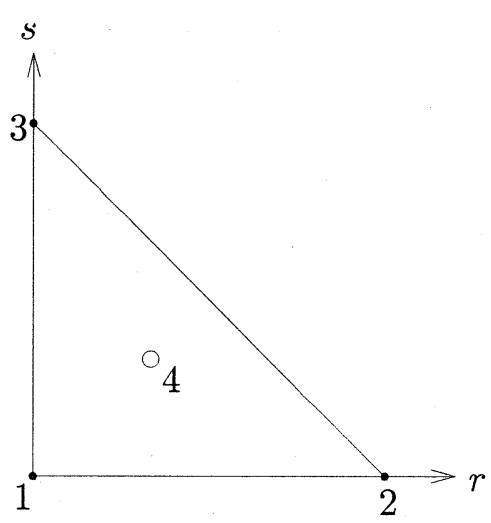

(a) 気泡関数要素

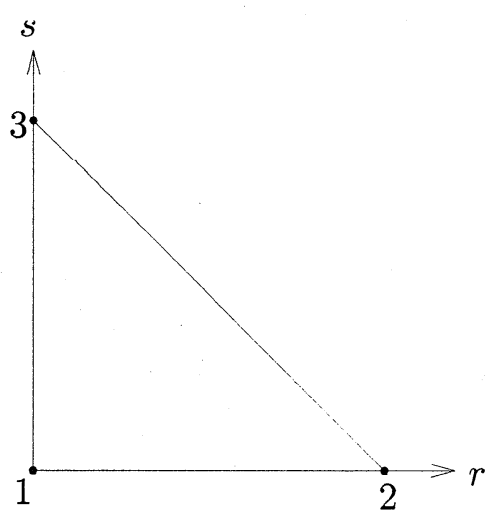

(b) 1 次要素

図-1 MINI 要素

\section{2 線形型気泡関数}

本研究では, 図ー 2 に示すように三角形の要素領域 をその重心点を用いて 3 つの小三角形 $w_{i}$ に分割する線 形型気泡関数を用いる. 線形型気泡関数はこの小三角
形毎にアイソパラメトリック座標系 $\{r, s\}$ を用いて次 のように定義される.

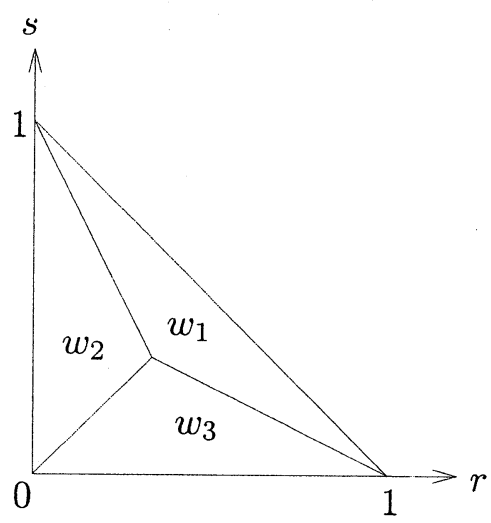

図-2 要素領域

$$
\phi_{B}= \begin{cases}3(1-r-s) & \text { in } w_{1} \\ 3 r & \text { in } w_{2} \\ 3 s & \text { in } w_{3}\end{cases}
$$

\section{3 有限要素方程式}

Petrov-Galerkin 法により有限要素近似を行う. 安定 化気泡関数要素を用いた有限要素近似では, 次の 1 次 要素の有限要素空間 $\bar{V}_{i}{ }^{h}, Q^{h}$ と気泡関数の空間 $V_{i}{ }^{\prime}, \hat{V}_{i}{ }^{\prime}$ を用いる。

$$
\begin{gathered}
\bar{V}_{i}^{h}=\left\{\bar{v}_{i}^{h} \in\left(C_{0}^{0}(\Omega)\right)^{2},\left.\bar{v}_{i}^{h}\right|_{\Omega_{k}} \in\left(P 1\left(\Omega_{k}\right)\right)^{2}\right\} \\
V_{i}^{h^{\prime}}=\left\{v_{i}^{h^{\prime}} \in\left(C_{0}^{0}(\Omega)\right)^{2},\left.v_{i}^{h^{\prime}}\right|_{\Omega_{k}} \in \phi_{B} v_{B i}^{\prime}, v_{B i}^{\prime} \in \mathbf{R}^{2}\right\} \\
\hat{V}_{i}^{h^{\prime}}=\left\{\hat{v}_{i}^{h^{\prime}} \in\left(C_{0}^{0}(\Omega)\right)^{2},\left.\hat{v}_{i}^{h^{\prime}}\right|_{\Omega_{k}} \in \varphi_{B} v_{B i}^{\prime}, v_{B i}^{\prime} \in \mathbf{R}^{2}\right\} \\
Q^{h}=\left\{q^{h} \in C_{0}^{0}(\Omega),\left.q^{h}\right|_{\Omega_{k}} \in P 1\left(\Omega_{k}\right), \int_{\Omega} q^{h} d \Omega=0\right\}
\end{gathered}
$$

ここで, $\phi_{B},\left\{\varphi_{B} ;\left\langle\varphi_{B}, 1\right\rangle_{\Omega_{k}}=0\right\}$ は要素領域 $\Omega_{k}$ をコ ンパクトな台とする気泡関数, 安定化気泡関数であり, $V_{i}^{h^{\prime}}, \hat{V}_{i}^{h^{\prime}}$ は気泡関数による近似空間に対応している. 有 限要素空間として速度場に対して $V_{i}^{h}=\bar{V}_{i}^{h} \oplus V_{i}^{h^{\prime}}$ を圧 力場に対して $Q^{h}$ を用いることにより, 有限要素近似 解 $\left(u_{i}^{h}, p^{h}\right) \in V_{i}^{h} \times Q^{h}$ を見いだす次の近似問題が得ら れる。

$$
\begin{gathered}
\left\langle\dot{u}_{i}^{h}, \hat{v}_{i}^{h}\right\rangle+\left\langle u_{j}^{h} u_{i, j}^{h}, \hat{v}_{i}^{h}\right\rangle+\left\langle p_{, i}^{h}, \hat{v}_{i}^{h}\right\rangle \\
-\left\langle\nu\left(u_{i, j}^{h}+u_{j, i}^{h}\right)_{j}, \hat{v}_{i}^{h}\right\rangle=0 \quad \forall \hat{v}_{i}^{h} \in \hat{V}_{i}^{h} \\
\left\langle u_{i, i}^{h}, q^{h}\right\rangle=0 \quad \forall q^{h} \in Q^{h}
\end{gathered}
$$


ここで, $\langle u, v\rangle=\sum_{k=1}^{N_{k}}\langle u, v\rangle_{\Omega_{k}}=\sum_{k=1}^{N_{k}} \int_{\Omega_{k}} u v d \Omega$ で あり, $N_{k}$ は要素数である. 流速場に対して $V_{i}^{h}$ に属する 近似解 $u_{i}^{h}$ 亡 $\hat{V}_{i}^{h}=V_{i}^{h} \oplus \hat{V}_{i}^{h^{\prime}}$ に属する重み関数 $\hat{v}_{i}^{h}$ は 1 次 要素による補間関数の近似空間の元 $\bar{u}_{i}^{h}, \bar{v}_{i}^{h} \in \bar{V}_{i}^{h}$ および 気泡関数による近似空間の元 $u_{i}^{h^{\prime}}, v_{i}^{h^{\prime}} \in V_{i}^{h^{\prime}}, \hat{v}_{i}^{h^{\prime}} \in \hat{V}_{i}^{h^{\prime}}$ を用いて次のように表現できる.

$$
u_{i}^{h}=\bar{u}_{i}^{h}+u_{i}^{h^{\prime}}, \hat{v}_{i}^{h}=\bar{v}_{i}^{h}+v_{i}^{h^{\prime}}+\hat{v}_{i}^{h^{\prime}}=v_{i}^{h}+\hat{v}_{i}^{h^{\prime}}
$$

ここで

$$
\begin{gathered}
\bar{u}_{i}^{h}, \bar{v}_{i}^{h} \in \bar{V}_{i}^{h}, u_{i}^{h^{\prime}}=\sum_{k=1}^{N_{k}} \phi_{B} u_{B i}^{\prime} \in V_{i}^{h^{\prime}} \\
v_{i}^{h^{\prime}}=\sum_{k=1}^{N_{k}} \phi_{B} v_{B i}^{\prime} \in V_{i}^{h^{\prime}}, \hat{v}_{i}^{h^{\prime}}=\sum_{k=1}^{N_{k}} \varphi_{B} v_{B i}^{\prime} \in \hat{V}_{i}^{h^{\prime}}
\end{gathered}
$$

である. 安定化気泡関数要素を適用した有限要素方程 式は，以下のように書きかえることができる.

$$
\begin{gathered}
\left\langle\dot{u}_{i}^{h}, v_{i}^{h}\right\rangle+\left\langle u_{j}^{h} u_{i, j}^{h}, v_{i}^{h}\right\rangle \\
+\left\langle p_{, i}^{h}, v_{i}^{h}\right\rangle-\left\langle\nu\left(u_{i, j}^{h}+u_{j, i}^{h}\right)_{, j}, v_{i}^{h}\right\rangle \\
+\sum_{k=1}^{N_{k}}\left\langle\nu_{i j}^{\prime}\left(u_{i, j}^{h^{\prime}}+u_{j, i}^{h^{\prime}}\right), v_{i, j}^{h^{\prime}}\right\rangle_{\Omega_{k}} \\
=0 \quad \forall v_{i}^{h} \in V_{i}^{h} \\
\left\langle u_{i, i}^{h}, q^{h}\right\rangle=0 \quad \forall q^{h} \in Q^{h}
\end{gathered}
$$

$\nu_{i j}^{\prime}:=\frac{\left\langle\dot{u}_{i}^{h}+u_{j}^{h} u_{i, j}^{h}+p_{, i}^{h}-\nu\left(u_{i, j}^{h}+u_{j, i}^{h}\right)_{, j}, \varphi_{B}\right\rangle_{\Omega_{k}}}{\left\langle\left(u_{i, j}^{h^{\prime}}+u_{j, i}^{h^{\prime}}\right), \phi_{B, j}\right\rangle_{\Omega_{k}}}$

式 (14) の $\sum_{k=1}^{N_{k}}\left\langle\nu_{i j}^{\prime}\left(u_{i, j}^{h^{\prime}}+u_{j, i}^{h^{\prime}}\right), v_{i, j}^{h^{\prime}}\right\rangle_{\Omega_{k}}$ は安定化気泡関 数による安定化作用を制御する項である. 有限要素方 程式 (14),(15) の弱形式を適用した有限要素方程式は式 (16),(17)のように表すことができる.

$$
\begin{gathered}
\left\langle\dot{u}_{i}^{h}, v_{i}^{h}\right\rangle+\left\langle u_{j}^{h} u_{i, j}^{h}, v_{i}^{h}\right\rangle-\left\langle p^{h}, v_{i, i}^{h}\right\rangle \\
+\left\langle\nu\left(\bar{u}_{i, j}^{h}+\bar{u}_{j, i}^{h}\right), v_{i, j}^{h}\right\rangle+\left\langle\nu\left(u_{i, j}^{h^{\prime}}+u_{j, i}^{h^{\prime}}\right), v_{i, j}^{h}\right\rangle \\
+\sum_{k=1}^{N_{k}}\left\langle\nu_{i j}^{\prime}\left(u_{i, j}^{h^{\prime}}+u_{j, i}^{h^{\prime}}\right), v_{i, j}^{h^{\prime}}\right\rangle_{\Omega_{k}} \\
=\left\langle t_{i}, v_{i}^{h}\right\rangle_{\Gamma} \quad \forall v_{i}^{h} \in V_{i}^{h} \\
\left\langle u_{i, i}^{h}, q^{h}\right\rangle=0 \quad \forall q^{h} \in Q^{h}
\end{gathered}
$$

また，以下のような関係式が成り立つ.

$$
\begin{aligned}
& \left\langle\bar{u}_{i, j}^{h}, v_{i, j}^{h^{\prime}}\right\rangle=0,\left\langle u_{i, j}^{h^{\prime}}, \bar{v}_{i, j}^{h}\right\rangle=0 \\
& \left\langle\bar{u}_{j, i}^{h}, v_{i, j}^{h^{\prime}}\right\rangle=0,\left\langle u_{j, i}^{h^{\prime}}, \bar{v}_{i, j}^{h}\right\rangle=0
\end{aligned}
$$

式 (18),(19) を式 (16) に代入することにより, 有限要 素方程式 (16),(17) は, 次のように書き換えることがで きる.

$$
\begin{gathered}
\left\langle\dot{u}_{i}^{h}, v_{i}^{h}\right\rangle+\left\langle u_{j}^{h} u_{i, j}^{h}, v_{i}^{h}\right\rangle-\left\langle p^{h}, v_{i, i}^{h}\right\rangle \\
+\left\langle\nu\left(\bar{u}_{i, j}^{h}+\bar{u}_{j, i}^{h}\right), \bar{v}_{i, j}^{h}\right\rangle \\
+\sum_{k=1}^{N_{k}}\left\langle\left(\nu+\nu_{i j}^{\prime}\right)\left(u_{i, j}^{h^{\prime}}+u_{j, i}^{h^{\prime}}\right), v_{i, j}^{h^{\prime}}\right\rangle_{\Omega_{k}} \\
=\left\langle t_{i}, v_{i}^{h}\right\rangle_{\Gamma} \quad \forall v_{i}^{h} \in V_{i}^{h} \\
\left\langle u_{i, i}^{h}, q^{h}\right\rangle=0 \quad \forall q^{h} \in Q^{h}
\end{gathered}
$$

ここで

$$
\begin{gathered}
\left\langle\left(\nu+\nu_{i j}^{\prime}\right)\left(u_{i, j}^{h^{\prime}}+u_{j, i}^{h^{\prime}}\right), v_{i, j}^{h^{\prime}}\right\rangle_{\Omega_{k}}=\frac{\left\langle\phi_{B}, 1\right\rangle_{\Omega_{k}}^{2}}{A_{k}} \tau_{e S}^{-1} u_{B i}^{\prime} v_{B i}^{\prime} \\
\tau_{e S}=\left[\left(\frac{2\left|u_{i}\right|}{h_{k}}\right)^{2}+\left(\frac{4 \nu}{h_{k}^{2}}\right)^{2}\right]^{-\frac{1}{2}}
\end{gathered}
$$

$h_{k}$ : 各要素の代表長さ, $A_{k}$ : 各要素の面積

である. 一般的に, 非圧縮 Navier-Stokes 方程式などの 移流拡散方程式系の方程式は，その計算を安定にかつ 高精度に行うために安定化項の考慮が必要である. 式 (20),(21) をみるとこの安定化項は式 (20) の左辺第 5 項 の重心点の項のみである。これは，計算を安定にかつ 高精度に行うための安定化項の考慮を行う手法である SUPG/PSPG 法12)，BTD 法13)などの安定化項に比べ てその数が極端に少なくかつ, 非常にその項が簡単な ものである. また, 安定化気泡関数法は気泡関数の形 状は固定して, その代わりに安定化気泡関数を導入し, 式 (22) によって安定化の適切な作用を制御するのみで 良いので, 気泡関数の形状を变化させて精度の向上を 図る気泡関数の方法 ${ }^{14) 15) 16)}$ と比較しても定式化が簡便 になる。

\section{4. 形状同定解析}

\section{1 評価関数}

有限要素方程式 (20),(21) を，以下のように書き表す.

$$
\begin{array}{r}
v_{i}^{T}\left(\bar{M} \dot{u}_{i}+S\left(\bar{u}_{j}\right) u_{i}-B p-M_{\Gamma} t_{i}\right)=0 \quad \text { in } \quad \Omega(23) \\
q^{T}\left(B^{T} u_{i}\right)=0 \quad \text { in } \quad \Omega \\
u_{i\left(t_{0}\right)}=\hat{u}_{i 0} \quad \text { on } \quad \Omega
\end{array}
$$

ここで, $\bar{M}$ は集中質量行列, $S\left(\bar{u}_{j}\right)$ は移流項（移流速 度 $\bar{u}_{j}$ は要素内 3 点平均值）之粘性項の行列, $B$ は勾 
配行列, $M_{\Gamma} t_{i}$ は境界積分の項である. 本研究で定義さ れる形状同定とは, 以下に示すような, 流体力を用い た評価関数を最小にする最適移動量を決定する問題で ある。

$$
J=\frac{1}{2} \int_{t_{0}}^{t_{f}}\left(e_{\Gamma_{B}}^{T} M_{\Gamma} t_{i}-D_{i}\right)^{T} Q_{i}\left(e_{\Gamma_{B}}^{T} M_{\Gamma} t_{i}-D_{i}\right) d t
$$

ここで,

$$
\begin{gathered}
e_{\Gamma_{B}}^{T} M_{\Gamma} t_{i}=-\int_{\Gamma_{B}} t_{i} d \Gamma \\
e_{\Gamma_{B}}^{T}=[0,0,0,1,1,1, \ldots, 0,0,0]
\end{gathered}
$$

である. $e_{\Gamma_{B}}^{T} M_{\Gamma} t_{i}$ および $D_{i}$ は, 物体表面上における 流体力の計算値と目的值を表す. $e_{\Gamma_{B}}^{T}$ ベクトル成分は, 境界上の節点において対象とする物体 $B$ 上の節点では 1, その他の部分では 0 とする.

\section{2 随伴方程式}

有限要素方程式を考慮して, 評価関数 $J$ を以下のよ うに拡張する.

$J^{*}=J+\int_{t_{0}}^{t_{f}} \lambda_{u_{i}}^{T}\left(-S\left(\bar{u}_{j}\right) u_{i}+B p+M_{\Gamma} t_{i}-\bar{M} \dot{u}_{i}\right) d t$

$$
+\int_{t_{0}}^{t_{f}} \lambda_{p}^{T}\left(B^{T} u_{i}\right) d t=\int_{t_{0}}^{t_{f}}\left\{H-\lambda_{u_{i}}^{T}\left(\bar{M} \dot{u}_{i}\right)\right\} d t
$$

ここで,

$$
\begin{aligned}
& H=\frac{1}{2}\left(e_{\Gamma_{B}}^{T} M_{\Gamma} t_{i}-D_{i}\right)^{T} Q_{i}\left(e_{\Gamma_{B}}^{T} M_{\Gamma} t_{i}-D_{i}\right) \\
& +\lambda_{u_{i}}^{T}\left(-S\left(\bar{u}_{j}\right) u_{i}+B p+M_{\Gamma} t_{i}\right)+\lambda_{p}^{T}\left(B^{T} u_{i}\right)
\end{aligned}
$$

である. $\lambda_{u_{i}}, \lambda_{p}$ はそれぞれ流速, 圧力に対するラグ ランジュ乗数を表す. すなわち, 拡張された評価関数 $J^{*}$ に扩いて拘束条件こして有限要素方程式を满足し, かつ評価関数 $J$ が全時間で最小化されることになる最 適移動量 $x_{j}$ を求めることになる. 次式のように $J^{*}$ の 第一変分をとり,

$$
\begin{aligned}
\delta J^{*} & =\delta \lambda_{u_{i}\left(t_{0}\right)}^{T} \bar{M} u_{i}\left(t_{0}\right)+\lambda_{u_{i}\left(t_{0}\right)}^{T} \delta \bar{M} u_{i}\left(t_{0}\right) \\
& +\lambda_{u_{i}\left(t_{0}\right)}^{T} \bar{M} \delta u_{i}\left(t_{0}\right)-\delta \lambda_{u_{i}\left(t_{f}\right)}^{T} \bar{M} u_{i}\left(t_{f}\right) \\
& -\lambda_{u_{i}\left(t_{f}\right)}^{T} \delta \bar{M} u_{i}\left(t_{f}\right)-\lambda_{u_{i}\left(t_{f}\right)}^{T} \bar{M} \delta u_{i}\left(t_{f}\right) \\
& +\int_{t_{0}}^{t_{f}}\left\{\left(\frac{\partial H}{\partial u_{i}}\right)^{T} \delta u_{i}+\left(\frac{\partial H}{\partial p}\right)^{T} \delta p\right. \\
& +\left(\frac{\partial H}{\partial t_{i}}\right)^{T} \delta t_{i}+\left(\frac{\partial H}{\partial x_{j}}\right)^{T} \delta x_{j} \\
& +\left(\frac{\partial H}{\partial \lambda_{u_{i}}}\right)^{T} \delta \lambda_{u_{i}}+\left(\frac{\partial H}{\partial \lambda_{p}}\right)^{T} \delta \lambda_{p} \\
& +\delta \dot{\lambda}_{u_{i}\left(t_{0}\right)}^{T} \bar{M} u_{i}\left(t_{0}\right)+\dot{\lambda}_{u_{i}\left(t_{0}\right)}^{T} \delta \bar{M} u_{i}\left(t_{0}\right) \\
& \left.+\dot{\lambda}_{u_{i}\left(t_{0}\right)}^{T} \bar{M} \delta u_{i}\left(t_{0}\right)\right\} d t
\end{aligned}
$$

評価関数 $J^{*}$ の最小値を求める.

$$
\delta J^{*}=0
$$

上式の条件 (必要条件) により, ラグランジュ乗数に 対する随伴方程式が得られる.

$$
\begin{gathered}
\bar{M} \dot{\lambda}_{u_{i}}-\tilde{S}\left(u_{j}\right)^{T} \lambda_{u_{i}}+B \lambda_{p}=0 \quad \text { in } \quad \Omega \\
B^{T} \lambda_{u_{i}}=0 \quad \text { in } \quad \Omega \\
\lambda_{u_{i\left(t_{f}\right)}}=0 \quad \text { in } \quad \Omega \\
\lambda_{u_{i}}=-e_{\Gamma_{B}} Q_{i}\left(e_{\Gamma_{B}}^{T} M_{\Gamma} t_{i}-D_{i}\right) \quad \text { on } \Gamma
\end{gathered}
$$

式 (35) は,

$$
\begin{aligned}
\frac{\partial H}{\partial t_{i}} & =\left(e_{\Gamma_{B}}^{T} M_{\Gamma}\right)^{T} Q_{i}\left(e_{\Gamma_{B}}^{T} M_{\Gamma} t_{i}-D_{i}\right)+\lambda_{u_{i}}^{T} M_{\Gamma} \\
& =M_{\Gamma}^{T} e_{\Gamma_{B}} Q_{i}\left(e_{\Gamma_{B}}^{T} M_{\Gamma} t_{i}-D_{i}\right)+M_{\Gamma}^{T} \lambda_{u_{i}} \\
& =M_{\Gamma}^{T}\left[e_{\Gamma_{B}} Q_{i}\left(e_{\Gamma_{B}}^{T} M_{\Gamma} t_{i}-D_{i}\right)+\lambda_{u_{i}}\right]=0
\end{aligned}
$$

より,

$$
e_{\Gamma_{B}} Q_{i}\left(e_{\Gamma_{B}}^{T} M_{\Gamma} t_{i}-D_{i}\right)+\lambda_{u_{i}}=0
$$

となる.

\section{5. 時間方向の離散化}

\section{1 状態方程式}

時間方向の離散化には, 安定性に優れ時間增分を大 きくとれる陰的解法を適用し, 連続式 (24) は完全陰的 に表す.

$$
\begin{gathered}
\bar{M} \frac{u_{i}^{n+1}-u_{i}^{n}}{\Delta t}+S\left(\bar{u}_{i}^{*}\right) u_{i}^{n+1 / 2}-B p^{n+1}=M_{\Gamma_{2},} t_{i} \\
B^{T} u_{i}^{n+1}=0
\end{gathered}
$$

ここで,

$$
\bar{u}_{i}^{*}=\frac{1}{2}\left(3 \bar{u}_{i}^{n}-\bar{u}_{i}^{n-1}\right), u_{i}^{n+1 / 2}=\frac{1}{2}\left(u_{i}^{n+1}+u_{i}^{n}\right)
$$

である. 圧力 Poisson 方程式の導出については, 運動方 程式 (38) と連続式 (39) に対して, 連続式 (39) を完全 に満足しない中間流速を導入してから圧力 Poisson 方 程式を導くことによって流速場と圧力場を分離して解 くことのできる分離型法を適用する. 前時間ステップ の圧力 $p^{n}$ を近似的な圧力として, 運動方程式 (38) の 圧力を $p^{n}$ に置き換えると, 運動方程式 (38) は, 未知 流速 $u_{i}^{n+1}$ を中間流速 $\tilde{u}_{i}^{n+1}$ に置き換えた次式になる.

$$
\bar{M} \frac{\tilde{u}_{i}^{n+1}-u_{i}^{n}}{\Delta t}+S\left(\bar{u}_{i}^{*}\right) \tilde{u}_{i}^{n+1 / 2}-B p^{n}=M_{\Gamma_{2}} t_{i}
$$


ここで,

$$
\tilde{u}_{i}^{n+1 / 2}=\frac{1}{2}\left(\tilde{u}_{i}^{n+1}+u_{i}^{n}\right)
$$

である. 式 (38) と式 (40) の差をとると, 次式が得ら れる。

$$
\begin{gathered}
\bar{M} \frac{u_{i}^{n+1}-\tilde{u}_{i}^{n+1}}{\Delta t}+\frac{1}{2} S\left(\bar{u}_{i}^{*}\right)\left(u_{i}^{n+1}-\tilde{u}_{i}^{n+1}\right) \\
-B\left(p^{n+1}-p^{n}\right)=0
\end{gathered}
$$

式 (41) に $B^{T} \bar{M}^{-1}$ をかけ, 式 (39) を代入することに よって圧力 Poisson方程式が得られる. だたし, $u_{i}^{n+1} \simeq$ $\tilde{u}_{i}^{n+1}$ と仮定し, ここでは, 式 (41) の右辺における $B^{T} \tilde{u}^{n+1}$ 以外の項は省略している.

$$
B^{T} \bar{M}^{-1} B \Delta t\left(p^{n+1}-p^{n}\right)=-B^{T} \tilde{u}_{i}^{n+1}
$$

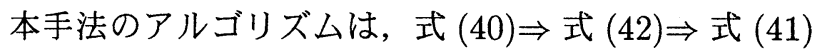
となる.

\section{2 随伴方程式}

状態方程式の時間方向の離散化と同様に, 安定性に 優れ時間増分を大きくとれる陰的解法を適用し, 随伴 方程式に対する連続式 (33) は完全陰的に表す.

$$
\begin{gathered}
\bar{M} \frac{\lambda_{u_{i}}^{n-1}-\lambda_{u_{i}}^{n}}{\Delta t}+\tilde{S}^{T}\left(u_{j}\right) \lambda_{u_{i}}^{n-1 / 2}-B \lambda_{p}^{n-1}=0 \\
B^{T} \lambda_{u_{i}}^{n-1}=0
\end{gathered}
$$

ここで,

$$
\lambda_{u_{i}}^{n-1 / 2}=\frac{1}{2}\left(\lambda_{u_{i}}^{n-1}+\lambda_{u_{i}}^{n}\right)
$$

である. 圧力のラグランジュ乗数に対する Poisson 方 程式の導出については, 運動方程式 (43) と連続式 (44) に対して, 連続式 (44) を完全に満足しない中間流速を 導入してから圧力のラグランジュ乗数に対する Poisson 方程式を導くことによって流速場と圧力場を分離して 解くことのできる分離型法を適用する．本手法のアル ゴリズムは以下のようになる.

$$
\begin{gathered}
\bar{M} \frac{\tilde{\lambda}_{u_{i}}^{n-1}-\lambda u_{i}^{n}}{\Delta t}+\tilde{S}^{T}\left(u_{j}\right) \tilde{\lambda}_{u_{i}}^{n-1 / 2}-B \lambda p^{n}=0 \\
B^{T} \bar{M}^{-1} B \Delta t\left(\lambda_{p}^{n-1}-\lambda_{p}^{n}\right)=-B^{T} \tilde{\lambda}_{u_{i}}^{n-1} \\
\bar{M} \frac{\lambda_{u_{i}}^{n-1}-\tilde{\lambda}_{u_{i}}^{n-1}}{\Delta t}+\frac{1}{2} \tilde{S}^{T}\left(u_{j}\right)\left(\lambda u_{i}^{n-1}-\tilde{\lambda}_{u_{i}}^{n-1}\right) \\
-B\left(\lambda_{p}^{n-1}-\lambda_{p}^{n}\right)=0
\end{gathered}
$$

ここで,

$$
\tilde{\lambda}_{u_{i}}^{n-1 / 2}=\frac{1}{2}\left(\tilde{\lambda}_{u_{i}}^{n-1}+\lambda_{u_{i}}^{n}\right)
$$

である.

\section{Sakawa-Shindo 法}

最小化手法として, Sakawa-Shindo 法17)を用いる. この方法は, 評価関数 $J$ において, 以下に示すような ペナルティ項を導入した修正評価関数を用いて最小化 をはかるものである.

$$
K^{(l)}=J^{*(l)}+\frac{1}{2}\left(x_{j}^{(l+1)}-x_{j}^{(l)}\right)^{T} c^{(l)}\left(x_{j}^{(l+1)}-x_{j}^{(l)}\right)
$$

ここで, $(l)$ は反復回数, $c^{(l)}$ は重み（対角）行列であ る. また, 式 (48) の右辺第二項, すなわち, ペナルティ 項 $\frac{1}{2}\left(x_{j}^{(l+1)}-x_{j}^{(l)}\right)^{T} c^{(l)}\left(x_{j}^{(l+1)}-x_{j}^{(l)}\right)$ は, 繰り返し計算 の初期における計算が不安定になるのを防ぐために用 いられるものである．この修正評価関数において停留 条件 $\frac{\partial K^{(l)}}{\partial x_{j}^{(l)}}=0$

$$
\left[\int_{t_{0}}^{t_{f}}\left\{\frac{\partial H}{\partial x_{j}^{(l)}}\right\}^{T} d t-c^{(l)}\left(x_{j}^{(l+1)}-x_{j}^{(l)}\right)\right]^{T} \delta x_{j}^{(l)}=0
$$

を適用することにより次式を得る.

$$
\begin{gathered}
x_{j}^{(l+1)}=x_{j}^{(l)}+c^{(l)} \int_{t_{0}}^{t_{f}}\left\{\lambda _ { u _ { i } } ^ { T } \left[-\left\{\frac{\partial S\left(\bar{u}_{j}\right)}{\partial x_{j}^{(l)}}\right\} u_{i}\right.\right. \\
\left.\left.+\left\{\frac{\partial B}{\partial x_{j}^{(l)}}\right\} p\right]+\lambda_{p}^{T}\left\{\frac{\partial B^{T}}{\partial x_{j}^{(l)}}\right\} u_{i}\right\}^{T} d t
\end{gathered}
$$

ここで,

$$
\begin{aligned}
\frac{\partial H}{\partial x_{j}^{(l)}} & =\lambda_{u_{i}}^{T}\left[-\left\{\frac{\partial S\left(\bar{u}_{j}\right)}{\partial x_{j}^{(l)}}\right\} u_{i}+\left\{\frac{\partial B}{\partial x_{j}^{(l)}}\right\} p\right. \\
& \left.+\left\{\frac{\partial M_{L}}{\partial x_{j}^{(l)}}\right\} t_{i}\right]+\lambda_{p}^{T}\left\{\frac{\partial B^{T}}{\partial x_{j}^{(l)}}\right\} u_{i} \\
& +\left(e_{L}^{T}\left\{\frac{\partial M_{L}}{\partial x_{j}^{(l)}}\right\} t_{i}\right)^{T} Q_{i}\left(e_{L}^{T} M_{L} t_{i}-D_{i}\right) \\
& =\lambda_{u_{i}}^{T}\left[-\left\{\frac{\partial S\left(\bar{u}_{j}\right)}{\partial x_{j}^{(l)}}\right\} u_{i}+\left\{\frac{\partial B}{\partial x_{j}^{(l)}}\right\} p\right] \\
& +\lambda_{p}^{T}\left\{\frac{\partial B^{T}}{\partial x_{j}^{(l)}}\right\} u_{i} \\
& +t_{i}^{T}\left\{\frac{\partial M_{L}}{\partial x_{j}^{(l)}}\right\}^{T}\left[\lambda_{u_{i}}+e_{L} Q_{i}\left(e_{L}^{T} M_{L} t_{i}-D_{i}\right)\right] \\
& =\lambda_{u_{i}}^{T}\left[-\left\{\frac{\partial S\left(\bar{u}_{j}\right)}{\partial x_{j}^{(l)}}\right\} u_{i}+\left\{\frac{\partial B}{\partial x_{j}^{(l)}}\right\} p\right] \\
& +\lambda_{p}^{T}\left\{\frac{\partial B^{T}}{\partial x_{j}^{(l)}}\right\} u_{i}
\end{aligned}
$$


である. 式 (49) が, 同定すべき形状座標を求める式と なる.ここで, 重み行列 $c^{(0)}$ は, 以下のように定める.

$$
\begin{aligned}
c^{(0)}=( \pm) I \cdot \| \int_{t_{0}}^{t_{f}}\left\{\lambda_{u_{i}}^{T}\left[-\left\{\frac{\partial S\left(\bar{u}_{j}\right)}{\partial x_{j}^{(0)}}\right\} u_{i}+\left\{\frac{\partial B}{\partial x_{j}^{(0)}}\right\} p\right]\right. \\
\left.+\lambda_{p}^{T}\left\{\frac{\partial B^{T}}{\partial x_{j}^{(0)}}\right\} u_{i}\right\} d t \|_{\infty}^{T} / \Delta \hat{x}_{j \max }^{(1)}
\end{aligned}
$$

ここで, $\|\cdot\|_{\infty}$ は最大ノルム, $I$ は単位行列, $\Delta \hat{x}_{j \max }^{(1)}$ は $l=1$ 回目の最大移動量であり, $c^{(0)}$ の符号は $J^{(1)} \leq$ $J^{(0)}$ となるように指定する. また, 修正評価関数のぺ ナルティ項の影響は, 同定形状座標 $x_{j}^{(l+1)}$ が収束する $x_{j}^{(l+1)} \simeq x_{j}^{(l)}$ につれて, 少なくなるものである.よつ $\tau$, 同定形状座標 $x_{j}^{(l+1)}$ が収束するときは, 修正評価 関数は評価関数と同值となる．このアルゴリズムは以 下のようになる.

1. $l=0$ とし初期形状 $x_{j}^{(0)}$ を設定する.

2. 式 (23),(24) を用いて状態量 $u_{i}^{(l)}, p^{(l)}$ を求める.

3. 式 (26) を用いて評価関数 $J^{(l)}$ を求める.

4. 式 (32),(33) を用いて随伴量 $\lambda_{u_{i}}^{(l)}, \lambda_{p}^{(l)}$ を求める.

5. 式 (49) を用いて同定形状座標 $x_{j}^{(l+1)}$ を求める.

6. 誤差ノルム $e=\left\|x_{j}^{(l+1)}-x_{j}^{(l)}\right\|_{\infty}$ を計算し, $e<$ єなら計算を終了する，そうでなければ，次のス テップに進む.

7. 式 (23),(24) を用いて状態量 $u_{i}^{(l+1)}, p^{(l+1)}$ を求 める.

8. 式 $(26)$ を用いて評価関数 $J^{(l+1)}$ を求める.

9. 重み行列 $c^{(l)}$ を次のように修正する. $J^{(l+1)} \leq J^{(l)}$ ならば $c^{(l+1)}=0.9 c^{(l)}, l+1 \rightarrow l$ と してステップ 4 へ, そのほかは $c^{(l)}=2.0 c^{(l)}$ とし ステップ 5 ヘ.

\section{7. 解析例}

形状同定解析の検証問題として流体力を評価関数に 用いた円柱周りの解析を行う.この解析は, 目的とす る流体力（抗力）の值を評価関数に設定し, 円形状か ら逆解析を開始して, 評価関数が最小となるような形 状を求める問題である. 解析領域および有限要素メッ シュを図ー 3,4 に示す. 図一 4 の有限要素メッシュの節 点数, 要素数は 1834,3500 であり円柱の周りを 56 分 割している. 形状同定解析を行うための円柱の初期形 状の直径 D は 1.0 を設定した. 解析例としては, レイ ノルズ数 0.1 (Stokes 流れとなる領域), 20 (カルマン渦 の発生しない領域），250（カルマン渦が発生する領域）
の 3 ケースを行った. 時間増分量は 0.4 を用い, 評価 関数で用いる始端時間, 終端時間は $t_{0}=200, t_{f}=300$ としている. 始端時間を $t_{0}=200$ とした理由は, 非定 常解析であるので, 現象が十分に定常解または周期解 に移行した時間からの抗力をコントロールすることを 考慮したためである．また，Sakawa-Shindo 法で使用 する初期設定量 $\Delta \hat{x}_{j \text { max }}^{(1)}, \varepsilon$ はそれぞれ $10^{-2}, 10^{-5}$ と した.

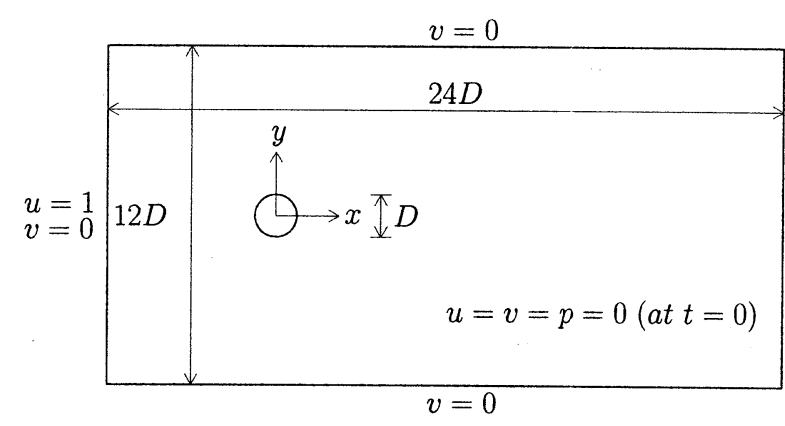

図-3 解析領域

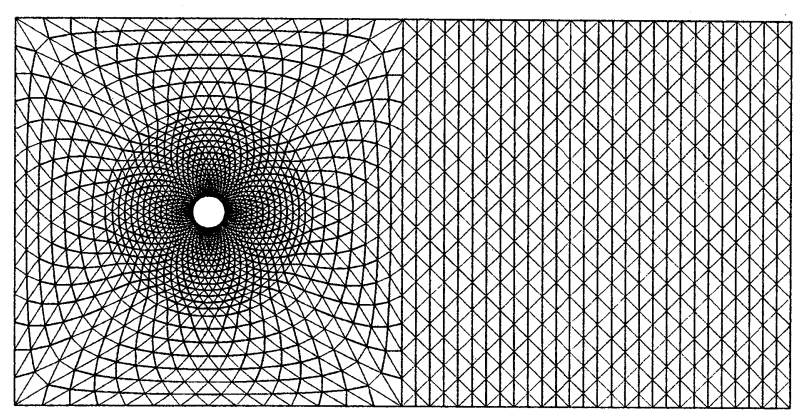

図-4 有限要素メッシュ

\section{1 解析例 $1(\mathrm{Re}=0.1)$}

図ー5にレイノルズ数 0.1(Stokes 流れとなる領域) を 用いた場合の同定された抗力, 形状を示す. 同定形状 を求めるために要した反復回数は 36 であった. 図ー 5 を見ると同定された形状における抗力の值が非常によ く目的值の抗力に一致している. 考察としては, 本解 析は形状同定問題であるので最適形状問題ではないが, 得られた形状は最適形状問題で得られている Ganesh 7 ), 片峯ら ${ }^{8)}$ の形状と類似した楕円形状になっている.

\section{2 解析例 $2(\mathrm{Re}=20)$}

図ー6にレイノルズ数 20 を用いた場合の同定され た抗力, 形状を示す. 同定形状を求めるために要した 反復回数は 28 であった.レイノルズ数 20 の領域では, 
円柱周りの解析においてカルマン渦は発生しないので 定常解となり，抗力は図一6のように一定值に収束す る. 図一 6 を見ると同定された形状における抗力の值 が非常によく目的值の抗力に一致している. 同定され た形状をみると,レイノルズ数 0.1 の場合と同様に最 適形状問題で得られている Ganesh ${ }^{7)}$, 片峯ら ${ }^{8)}$ の結果 と類似した形状となっており流れに向かって少し尖っ た卵形になっている.

\section{3 解析例 $3(\mathrm{Re}=250)$}

図ー7にレイノルズ数 250 を用いた場合の同定され た抗力, 形状を示す. 同定形状を求めるために要した 反復回数は 37 であった. レイノルズ数 250 の領域では, 円柱周りの解析においてカルマン渦が発生し周期解と なるので, 抗力は図一 7 のようにある周期をもった振 動した值となる.図一 7 を見ると同定された形状にお ける抗力の值が目的值の抗力の付近で振動しているこ とが解る. 同定された形状をみると, レイノルズ数 20 で得られた形状を角ばらしたような形になっている。

\section{8. 結言}

本研究では, 従来の安定化手法に比べて定式化が極 めて簡便な安定化気泡関数要素を用いた非定常問題に おける形状同定解析を提案した。また、評価関数に流 体力を用いた非圧縮 Navier-Stokes 方程式における形 状同定解析の適用を検討した. 検証の問題として, レ イノルズ数 0.1(Stokes 流れとなる領域), 20 (カルマン 渦の発生しない領域）, 250（カルマン渦が発生する領 域）の 3 ケースの抗力の同定形状解析を行った. 3 ケー スいずれの場合においても目的とした抗力を得るでき る同定形状を解析することができた，考察として，同 定解析で得られした同定形状は最適形状問題で得られて いる形状と類似した形状になっている. 今後は, より 高いレイノルズ数における形状同定解析の検討を行っ ていく所存である.

\section{参考文献}

1) O.Pironneau :On optimum profiles in Stokes flow, $J$. Fluid Mech., 59, Part 1, pp.117, 1973.

2) O.Pironneau :On optimum design in fluid mechanics, J. Fluid Mech., 64, Part 1, pp.97, 1974.

3) J.M.Bourot :On the numerical computation of the optimum profile in Stokes flow, J. Fluid Mech., 65, Part 3, pp.513, 1975.

4) 佐野, 酒井: Stokes 流中における最小抗力物体形状の数 值的决定（二次元有限領域で断面積一定の場合），日本航 空宇宙学会誌, 30, 339, pp.207, 1982.

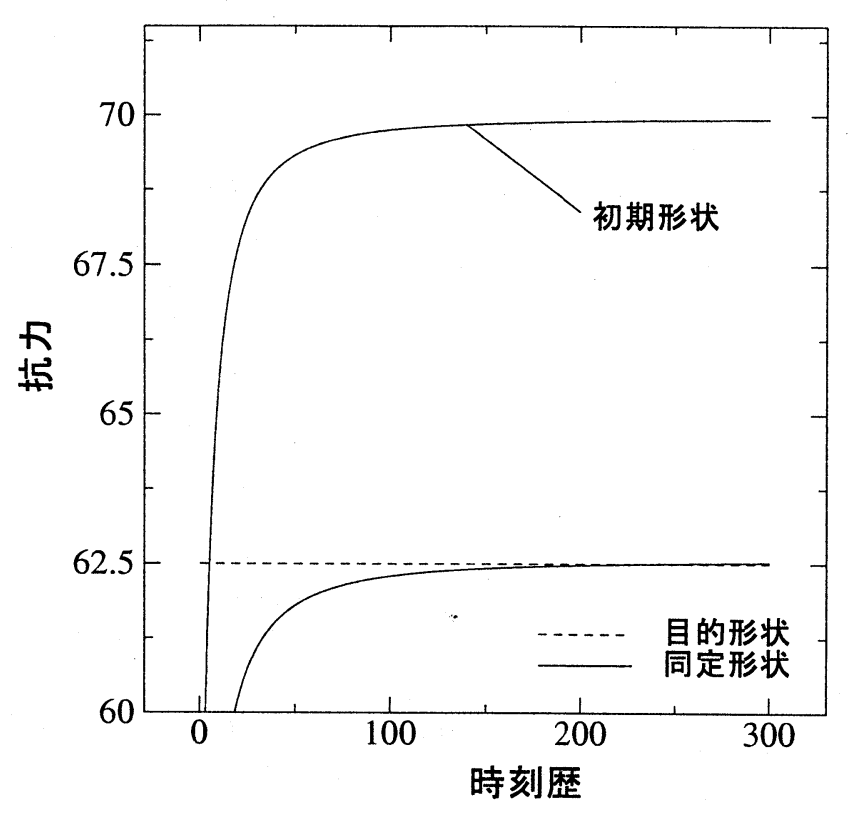

(a) 抗力

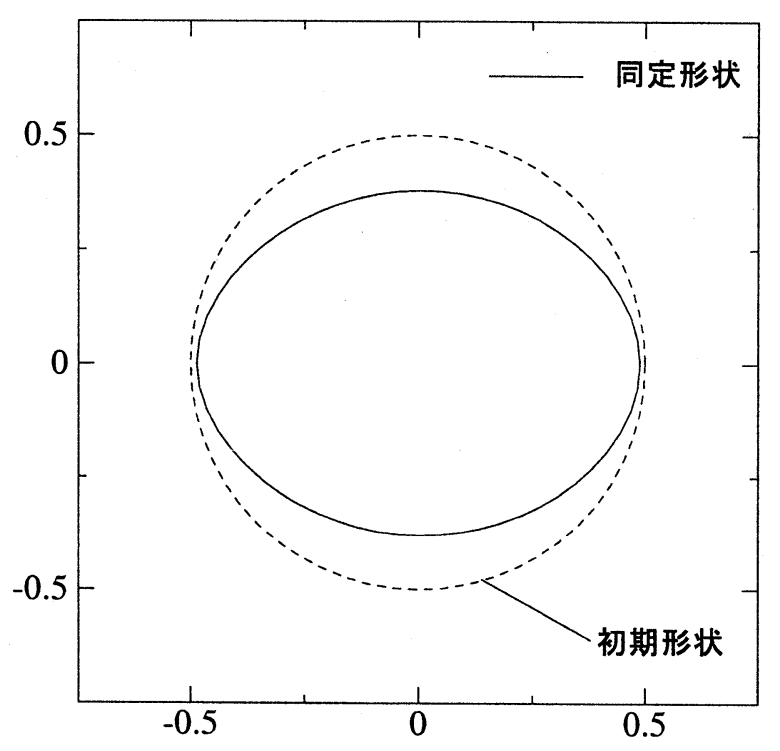

(b) 形状

図-5 同定された抗力と形状 $(\mathrm{Re}=0.1)$

5) 別所, 姫野:2 次元 Stokes 流れにおける最適形状につい て, 関西造船協会誌, 193, pp.115, 1985.

6) 畔上:領域最適化問題の一解法，日本機械学会論文集 A, 60, 574, pp.165, 1994.

7) R.K.Ganesh :The minimun drag profile in laminar flow: a numerical, Transaction of the ASME, J. Fluids Engng., 116, pp.456-462, 1994.

8) 片峯, 津幡, 畔上:粘性流れ場における形状最適化問題の 解法, 日本応用数理学会, 平成 14 年度年会, 2002 .

9) J.Matsumoto and M.Kawahara :Shape identification for fluid-structure interaction problem using improved bubble element, Int. J. Comput. Fluid Dynamics, 15, pp.33-45, 2001.

10) 松本, 梅津, 川原 : 線形型気泡関数を用いた非圧縮性 粘性流体解析と適応型有限要素法, 応用力学論文集, 2 , 


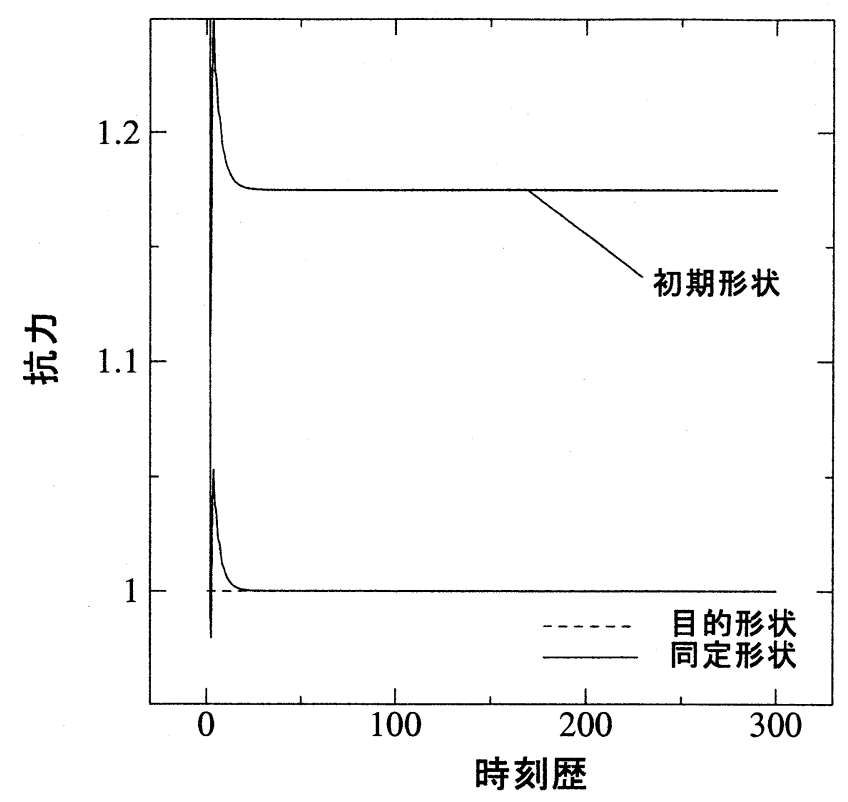

(a) 抗力

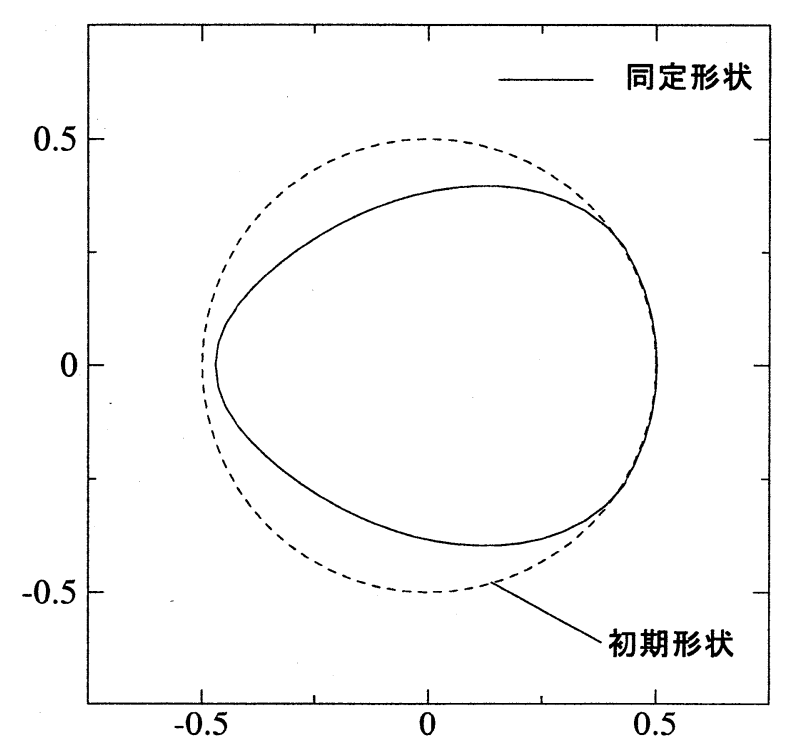

(b) 形状

図-6 同定された抗力と形状 $(R e=20)$

pp.223-232, 1999.

11) 松本純一：安定化気泡関数有限要素法による流体問題の 順 - 逆解析に関する計算力学的研究, 中央大学博士論文, 2003.

12) T.E.Tezduyar et al. :Incompressible flow computations with stabilized bilinear and linear equalorder-interpolation velocity-pressure element, Comput. Methods Appl. Mech. Engng., 95, pp.221-242, 1992.

13) 丸岡, 太田, 平野, 川原: 同次補間を用いた陰的有限要 素法による非圧縮粘性流れの解析, 構造工学論文集, $43 \mathrm{~A}$, pp.383-394, 1997.

14) J.C.Simo, F.Armero, and C.A.Taylor :Stable and time-dissipative finite element methods for the incompressible Navier-Stokes equations in advection dominated flows, Int. J. Num. Meth. Engng., 38, pp.1475-

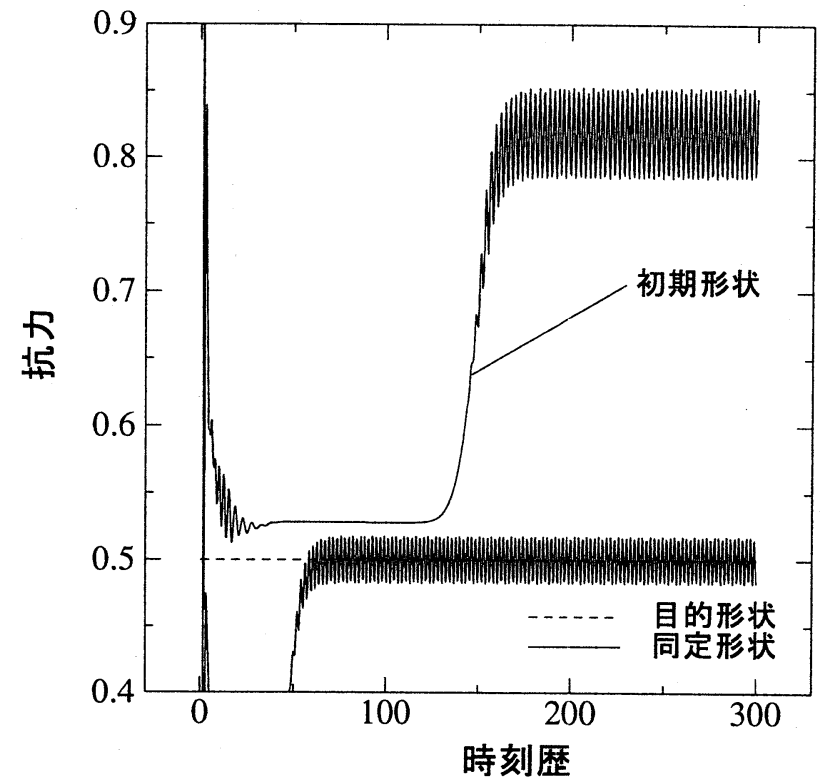

(a) 抗力

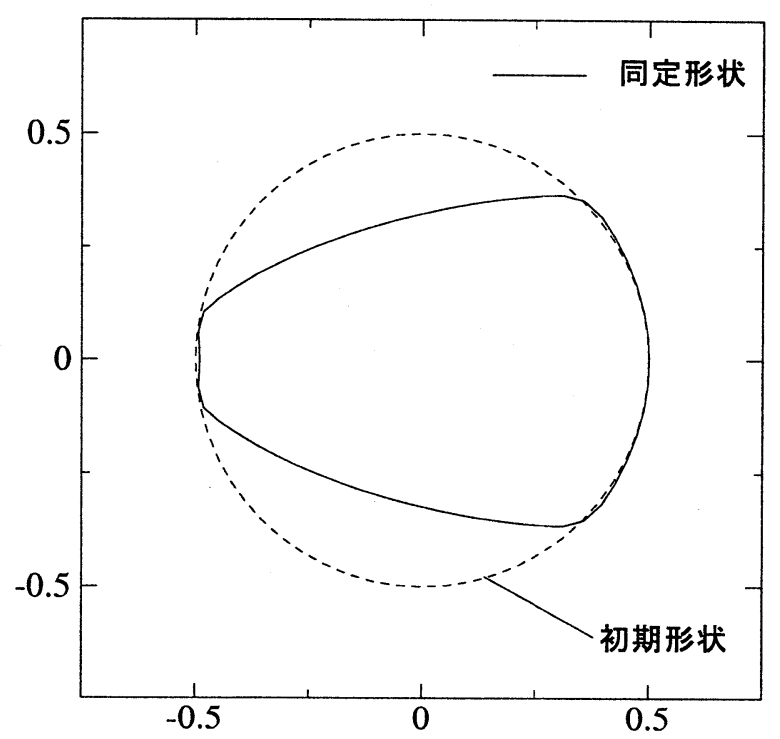

(b) 形状

図-7 同定された抗力と形状 $(\mathrm{Re}=250)$

1506, 1995.

15) T.Yamada :A bubble element for inviscid flow, Finite Elements in Fluids, 9, pp.1567-1576, 1995.

16) 奥村, 川原 : 気泡関数要素を用いた非圧縮 Navier-Stokes 方程式に対する Petrov-Galerkin 有限要素法, 応用力学論 文集, 4, pp.121-126, 2001.

17) Y.Sakawa and Y.Shindo :On global convergence of an algorithm for optimal control, Transactions on Automatic Control, IEEE, AC-25(6), pp.1149-1153, 1980.

（2003 年 4 月 18 日受付） 